\title{
Análise do perfil e das práticas dos auxiliares e técnicos de enfermagem em sala de vacina na Estratégia Saúde da Família
}

\author{
Francisco Rosemiro Guimarães Ximenes Neto, M.Sc.*, Patrícia Aragão Alves**, \\ Maristela Inês Osawa Chagas, D.Sc.***, Maria Alzeni Coelho Ponte****, Maria do Socorro Sousa Melo ${ }^{* * * * *}$, \\ Isabel Cristina Kowal Olm Cunha, D.Sc.*****
}

\begin{abstract}
*Enfermeiro Sanitarista, Docente do Curso de Enfermagem da Universidade Estadual do Vale do Acaraú-UVA, Sobral/CE, Doutorando e Membro do Grupo de Estudos e Pesquisa em Gestão e Gerenciamento em Saúde e Enfermagem-GEPAG da UNIFESP, Secretário da Saúde do município de Cariré, ${ }^{* *}$ Enfermeira graduada pela UVA, ${ }^{* *}$ Enfermeira, Diretora do Centro de Ciências da Saúde da UVA, ${ }^{* * * *}$ Enfermeira Obstetra, Docente do Curso de Enfermagem da UVA, Preceptora de Enfermagem da Escola de Formação em Saúde da Família Visconde de Sabóia, *****nfermeira, Especialista em Saúde da Família, Coordenadora da Atenção Primária à Saúde do Município de Sobral - Ceará, *****Enfermeira, Professora Adjunta e Lider Grupo de Estudos e Pesquisas em Administração em Saúde e Gerenciamento de Enfermagem-GEPAG da UNIFESP
\end{abstract}

\section{Resumo}

O estudo objetiva analisar as práticas dos auxiliares e técnicos de enfermagem que trabalham nas salas de vacina dos Centros de Saúde da Família da Estratégia Saúde da Família, além de descrever o perfil sociodemográfico destes. Trata-se de um estudo exploratório, com abordagem quantitativa, realizado em 28 Centros de Saúde da Família de Sobral/CE, entre setembro de 2007 e fevereiro de 2008. Os sujeitos do estudo são 22 (88\%) auxiliares de enfermagem e três (12\%) técnicos de enfermagem, que atuam exclusivamente na sala de vacina. Os resultados mostram que auxiliares e técnicos desenvolvem as mesmas práticas e assumem iguais responsabilidades, e estes precisam desenvolver mais açôes de educação em saúde na sala de vacina, além de vivenciar com os enfermeiros que os supervisionam processo de educação permanente sobre imunização e organização da sala de vacina.

Palavras-chave: Programa Saúde da Família, Enfermagem, educação em saúde.

\section{Abstract \\ Analysis of profile and practices of nursing auxiliaries and technicians in the vaccination room in the Family Health Strategy}

This study aims at analyzing the behavior of the nursing auxiliaries and technicians working in the vaccination rooms of Family Health Centers of Family Health Strategy, and their socio-demographic profile. It is an exploratory study, with quantitative approach, carried out in 28 Family Health Centers of Sobral/CE, from September 2007 to February 2008. The study was composed of $22(88 \%)$ nursing auxiliaries and three (12\%) nursing technicians,working exclusively in the vaccination room. The results point out that the auxiliaries and technicians develop the same practices and take the same responsibilities, and 
need to develop more effective health education in the vaccination room. They also experience permanent health education process with nurses supervisors related to immunization and organization of the vaccination room.

Key-words: Family Health Program, Nursing, health education.

\section{Resumen}

\section{Análisis del perfil y prácticas de auxiliares y técnicos de enfermería en la sala de vacunación en la Estrategia Salud de la Familia}

El estudio tiene como objetivo analizar las prácticas de auxiliares y técnicos de enfermería que trabajan en las salas de vacunación de Centros de Salud de la Familia de la Estrategia Salud de la Familia, además de describir el perfil sociodemográfico de estos profesionales. Se trata de un estudio exploratorio, con abordaje cuantitativo, realizado en 28 Centros de Salud de la Familia de Sobral - Ceará, entre septiembre de 2007 y febrero de 2008. Los sujetos del estudio son 22 (88\%) auxiliares de enfermería y tres (12\%) técnicos de enfermería, que actúan exclusivamente en la sala de vacunación. Los resultados muestran que auxiliares y técnicos desarrollan las mismas prácticas y asumen iguales responsabilidades, y necesitan desarrollar más acciones de educación en salud en la sala de vacunación, además de vivenciar con los enfermeros que los supervisan el proceso de educación permanente sobre inmunización y organización de la sala de vacunación.

Palabras-clave: Programa de Salud Familiar, Enfermería, educación en salud.

\section{Introdução}

A Estratégia Saúde da Família (ESF), criada em 1994 com a denominação de Programa Saúde da Família e, em 1997, efetivada como política organizativa da Atenção Primária à Saúde (APS) no Brasil vem incrementando o processo de descentralização e consolidação do Sistema Único de Saúde (SUS), contribuindo diretamente para a melhoria de indicadores de morbidade e mortalidade, principalmente, os relacionados à saúde materna e infantil.

O Ministério da Saúde (MS) aponta que o fortalecimento da ESF necessita “(...) ser sustentado por um processo que permita a real substituição da rede básica de serviços tradicionais no âmbito dos municípios, pela capacidade de produção de resultados práticos nos indicadores de saúde de qualidade de vida da população assistida" [1].

A Saúde da Família como estratégia estruturante dos sistemas municipais de saúde tem provocado um importante movimento com o intuito de reordenar o modelo de atenção no SUS. Busca maior racionalidade na utilizaçáo dos demais níveis assistenciais e tem produzido resultados positivos nos principais indicadores de saúde das populaçóes assistidas pelas equipes de saúde [2].

O trabalho em equipe da ESF é o elemento chave para a busca permanente de comunicação e troca de experiências e conhecimentos entre os integrantes. Para Peduzzi, o trabalho da equipe multiprofissional em saúde é uma forma de compensar a ultraespecializaçáo e recompor uma assistência integral. A autora afirma ainda que a noção de equipe deve estar etimologicamente associada à realização de tarefas, de trabalhos compartilhados entre sujeitos, que de seu conjunto de coletivo possa se extrair o sucesso para a realizaçáo pretendida [3].

A ESF em sua base organizativa exige uma equipe multiprofissional mínima, composta por um enfermeiro, um médico, seis a dez agentes comunitários de saúde e auxiliar de enfermagem. Tem sido comum, não por exigência normativa, encontrarmos técnicos de enfermagem em vez de auxiliares. É bem verdade, que a ESF oportuniza campo de trabalho para muitos trabalhadores da saúde.

O presente estudo apesar de discutir o processo de trabalho em equipe na ESF, trabalhar-se-á apenas com o auxiliar de enfermagem e o técnico de enfermagem, que desenvolvem açóes de promoção, proteção e recuperação da saúde no território, bem como executam açóes de orientação sanitária sob a supervisão do enfermeiro. De acordo com a Política Nacional da Atenção Básica, as atribuiçôes do auxiliar e do técnico de enfermagem na ESF são: "I - participar das atividades de assistência básica realizando procedimentos regulamentados no exercício de sua profissão na Unidade de Saúde da Família e, quando indicado ou necessário, no domicílio e/ou nos demais espaços comunitários (escolas, associaçóes etc.); II - realizar açóes de educação em saúde a 
grupos específicos e a famílias em situação de risco, conforme planejamento da equipe; e III - participar do gerenciamento dos insumos necessários para o adequado funcionamento da USF" [4].

Na prática, do dia a dia, o auxiliar e o técnico de enfermagem, no Centro de Saúde da Família (CSF) desenvolvem, além das açóes citadas, atividades técnicas em diferentes espaços, tais como as salas de esterilização, de aerossolterapia, de terapia de reidratação oral, de curativos, de medidas antropométricas, de vacina, entre outras.

No que concerne à sala de vacinação, esta é um espaço destinado à administração de imunobiológicos, cujas atividades são desenvolvidas pela equipe de enfermagem, com qualificação específica acerca da conservação, manipulaçáo e administraçáo dos imunobiológicos.

Assim, o presente estudo objetiva analisar as práticas dos auxiliares e técnicos de enfermagem que trabalham nas salas de vacina na ESF, além de descrever o perfil sociodemográfico destes.

\section{Material e métodos}

Trata-se de um estudo exploratório, com abordagem quantitativa. A pesquisa foi realizada em 28 CSF, sendo 14 na área urbana e igual número na rural do município de Sobral/CE, no período de setembro de 2007 a fevereiro de 2008. Sobral possui 48 equipes da ESF.

Os sujeitos do estudo foram 25 profissionais de enfermagem de nível técnico, sendo 22 (88\%) auxiliares de enfermagem e três (12\%) técnicos de enfermagem, que trabalham, exclusivamente, na sala de vacina dos CSF.

A coleta de dados foi realizada por meio de questionário contendo variáveis acerca do perfil sociodemográfico dos auxiliares e técnicos de enfermagem e das práticas destes nas salas de vacinas. Os questionários foram aplicados nos CSF da sede do município pelos pesquisadores e, na zona rural, pelos gerentes dos territórios da ESF. Os gerentes, antes da aplicação dos questionários, foram orientados quanto aos procedimentos.

Os questionários foram entregues aos auxiliares e técnicos de enfermagem, durante horário de trabalho, após a leitura e assinatura do Termo de Consentimento Livre e Esclarecido.

Os resultados foram analisados estatisticamente com cálculos de frequência absoluta e percentual e apresentados em forma de tabelas, com discussão de aspectos relevantes e interpretados à luz da literatura pertinente.

A pesquisa foi realizada respeitando os aspectos éticos e legais estabelecidos pela Resolução No 196/1996 do Conselho Nacional da Saúde. Os entrevistados tiveram livre arbítrio em participar da pesquisa, fornecendo-nos seu consentimento livre e esclarecido, em que se certificou de que não haveria riscos a sua saúde. Ressalta-se que esta pesquisa é um subprojeto de pesquisa intitulada 'Enfermagem no Território da Estratégia Saúde da Família: perfil, fazeres, saberes e necessidades de educação permanente dos enfermeiros, sendo seu Protocolo de Pesquisa aprovado pelo CEP da Universidade Estadual do Vale do Acaraú-UVA, sob o No. 392.

\section{Resultados e discussão}

\section{Perfil dos auxiliares e técnicos de enfermagem}

A descrição do perfil dos auxiliares e técnicos de enfermagem da ESF nesta pesquisa sobre o processo de trabalho na sala de vacina fez-se necessária pela importância que estes têm na organização e desenvolvimento do processo de trabalho da equipe e na prevenção de doenças no território da ESF.

Tabela I - Perfil sociodemográfico dos auxiliares e técnicos de enfermagem da ESF, Sobral/CE, fev 2008.

\begin{tabular}{|c|c|c|c|c|}
\hline \multirow[t]{2}{*}{ Variáveis } & Auxiliares & \multicolumn{3}{|c|}{ Técnicos } \\
\hline & $N^{\circ}$ & $N^{\circ}$ & $\%$ & \\
\hline \multicolumn{5}{|c|}{ Idade (anos) } \\
\hline 19 a 28 & 5 & & 23,0 & 1 \\
\hline 29 a 38 & 4 & & 18,0 & - \\
\hline 39 a 48 & 8 & & 36,0 & 1 \\
\hline 49 e mais & 5 & & 23,0 & 1 \\
\hline Total & 22 & & 100,0 & 3 \\
\hline \multicolumn{5}{|c|}{ Sexo } \\
\hline Feminino & 20 & & 91,0 & 3 \\
\hline Masculino & 2 & & 9,0 & - \\
\hline Total & 22 & & 100,0 & 3 \\
\hline \multicolumn{5}{|c|}{ Estado Civil } \\
\hline Casado & 10 & & 45,0 & 2 \\
\hline Solteiro & 7 & & 32,0 & 1 \\
\hline Companheiro Fixo & 2 & & 9,0 & - \\
\hline Separado/Divorciado & 3 & & 14,0 & - \\
\hline Total & 22 & & 100,0 & 3 \\
\hline \multicolumn{5}{|c|}{ Escolaridade } \\
\hline Ensino Fundamental & 2 & & 9,0 & - \\
\hline Completo & & & & \\
\hline $\begin{array}{l}\text { Ensino Médio Incom- } \\
\text { pleto }\end{array}$ & 1 & & 5,0 & - \\
\hline
\end{tabular}




\begin{tabular}{|c|c|c|c|c|c|}
\hline \multirow{2}{*}{ Variáveis } & \multicolumn{2}{|c|}{ Auxiliares } & \multicolumn{3}{|c|}{ Técnicos } \\
\hline & $\mathrm{N}^{\circ}$ & $\%$ & $\mathrm{~N}^{\circ}$ & $\%$ & \\
\hline Ensino Universitário & & 2 & & 9,0 & - \\
\hline Incompleto & & & & & \\
\hline Ensino Universitário & & 4 & & 18,0 & - \\
\hline Completo & & & & & \\
\hline Total & & 22 & & 100,0 & 3 \\
\hline Renda Mens & $|R \$|$ & lário & nimo & SM) & \\
\hline $1 \mathrm{SM}$ & & 3 & & 16 & 1 \\
\hline Acima de 1SM & & 17 & & 72 & 1 \\
\hline Não responderam & & 2 & & 12 & 1 \\
\hline Total & & 22 & & 100,0 & 3 \\
\hline
\end{tabular}

*O valor do salário mínimo em fevereiro de 2008 é de $\mathrm{R} \$ 380,00$, o equivalente a US\$217,51.

Dos sujeitos do estudo, 21 (84\%) eram auxiliares de enfermagem. $\mathrm{O}$ maior contingente de auxiliares de enfermagem em detrimento aos técnicos de enfermagem no SUS deve-se ao fato de que o Ministério da Saúde, por meio de uma política de educação na saúde denominada Programa de Profissionalização dos Trabalhadores da Área de Enfermagem (PROFAE) terem ascendido os históricos atendentes de enfermagem, que surgiram na Saúde Pública Brasileira em meados da década de 1970, a auxiliar de enfermagem na segunda metade da década de 1990. A extinçáo dos atendentes de enfermagem ocorreu com a promulgação da Lei do Exercício Profissional - Lei No 7.498/1986, daí o rápido aumento no contingente de auxiliares de enfermagem, em decorrência da profissionalização do atendente de enfermagem.

Especificamente, no que se refere à categoria dos auxiliares de enfermagem, o censo realizado pelo Conselho Federal de Enfermagem (COFEN) e pela Associação Brasileira de Enfermagem (ABEN), referente ao período 1982-1983, concluiu que existiam, na época, 64.289 auxiliares de enfermagem, 25.889 enfermeiros, 19.935 técnicos de enfermagem e 194.174 atendentes de enfermagem [5]. Girardi e Carvalho identificaram que, entre o período de 1995 e 2000, ocorreu um aumento de 22,1\% nos vínculos de emprego de auxiliares de enfermagem. Em 1995, existiam 199.899 auxiliares de enfermagem empregados, o equivalente a $24,5 \%$ do mercado dos profissionais de saúde, aumentando até o ano 2000 para $314.233,33,8 \%$ deste mercado. Configura-se, então, uma taxa crescente nos vínculos de emprego da categoria acima da média de todo os trabalhadores do setor saúde no período, que foi de $13,9 \%$ [6].
O emprego de trabalhadores da Enfermagem, segundo dados da Relaçáo Anual de Informaçóes Sociais (RAIS) e do Cadastro Geral de Empregados e Desempregados-CAGED do Ministério do Trabalho e Emprego, representa cerca de $30 \%$ do total do setor saúde, sendo que os enfermeiros representam quase $3,6 \%$; os auxiliares de enfermagem perto de $15 \%$ e os atendentes e demais categorias de pessoal auxiliar na área de enfermagem perto de $13 \%$ da força de trabalho dos serviços [7].

No caso da ESF, o quantitativo de auxiliares de enfermagem só é superado pelo de ACS. Com a expansão do PROFAE, muitos trabalhadores de saúde de diversas ocupaçóes, além do próprio atendente, buscaram ascender profissionalmente, com a oportunidade oferecida pelo projeto, almejando melhoria salarial e ascensão social. Nas unidades de saúde dos territórios da ESF, encontram-se sujeitos com formação técnica em auxiliar de enfermagem, mas desenvolvendo e ocupando funções que não são próprias da categoria, a exemplo do auxiliar de farmácia e de consultório dental.

Quanto à idade, os sujeitos do estudo estavam na faixa etária de 19 a 57 anos, sendo que existia uma prevalência no intervalo de idade de 39 a 48 anos, 36\%. Esta faixa etária nos remete a diversas interpretaçóes: uma delas é a valorização da experiência de vida no que se refere à vivência social e profissional, como também por representar um contingente de profissionais com mais experiência. Outro fato é que Sobral possuía um contingente significativo de atendentes de enfermagem descentralizados da Secretaria da Saúde do Estado para o município, que já vinham desenvolvendo suas ações no campo da Saúde Pública há vários anos, antes mesmo do processo de municipalização da saúde.

Dos sujeitos, 23 (92\%) eram do sexo feminino. Essa predominância, náo se trata de um fenômeno novo na Enfermagem, pois esta é uma profissão historicamente exercida por mulheres. A Organização Mundial da Saúde afirma que, “[...] em quase todos os países, as mulheres constituem a vasta maioria do pessoal de enfermagem e parteira. Em todas as partes, a Enfermagem é trabalho de mulher e tem as mesmas características de outras ocupaçóes em que predomina a mulher: baixa remuneração, condição inferior, deficientes condiçóes de trabalho, escassas perspectivas de promoção 
e formação deficiente" [8].

Em relação à renda, $72 \%$ dos pesquisados relataram perceber pouco mais de um salário mínimo, com remuneração mensal variando entre $\mathrm{R} \$ 388,00$ e 496,00. Daí, origina-se um dos motivos para a categoria de auxiliares de enfermagem não quererem se qualificar em técnicos de enfermagem, pois como se pode perceber, não há nenhum estímulo financeiro para estes profissionais.

Ministério da Saúde aponta que, as maiores oportunidades de emprego no segmento celetista do mercado de trabalho parecem estar reservadas aos trabalhadores com maior escolaridade, ao passo que se tornam mais escassas as oportunidades de emprego para trabalhadores menos escolarizados [7].

Ferretti questiona sobre as condiçóes objetivas para ofertar uma educação profissional que seja capaz de responder à produção e à atualização do conhecimento tecnológico e atender às demandas emergentes e às mudanças do mercado, já que existe uma redução dos gastos sociais, em particular, na Educação e na Saúde, e as precárias condiçóes na rede pública de ensino e há deficiência na formação de professores. Isso exige investimentos em pessoal, equipamentos, estrutura, material didático, entre outros, não necessariamente compatíveis com as demandas mais urgentes do mercado, as quais são em muitos casos, de caráter estritamente pragmático [9].

Em pesquisa realizada em seis municípios do Norte Cearense, com 38 auxiliares de enfermagem e 17 técnicos de enfermagem da ESF, identificou-se o seguinte perfil: auxiliares de enfermagem: $44,7 \%$ estavam na faixa etária de 31 a 40 anos de idade; $89 \%$ eram do sexo feminino; $42,1 \%$ eram casados; $50 \%$ apresentavam uma renda mensal de até um salário mínimo; $73,7 \%$ ensino médio completo; e, $47 \%$ atuavam na zona rural; técnicos de enfermagem: $52,9 \%$ estavam na faixa etária de 31 a 40 anos de idade; $84 \%$ eram do sexo feminino; $52,9 \%$ eram casados; $76,1 \%$ apresentavam uma renda mensal de até um salário mínimo; $94 \%$ ensino médio completo; e, $76,1 \%$ atuavam na zona urbana [10].

Pesquisa realizada pela $\mathrm{ABEn}$ sobre o perfil de ações do técnico de enfermagem no Brasil, em 2002, apontou o seguinte: $91 \%$ eram do sexo feminino; $52 \%$ estavam na faixa etária entre 30 a 45 anos;
$34 \%$ entre 26 a 35 anos; $51 \%$ eram casados e $40 \%$ solteiros [11].

Pesquisa realizada por Marsiglia, em 2004, com 901 auxiliares de enfermagem, sobre mercado de trabalho, mostrou que $91,3 \%$ eram do sexo feminino; $26,4 \%$ tinham entre 21 e 29 anos; $28,7 \%$, entre 30 e 39, e 28,2\%, entre 40 e 49 . Metade deles era formalmente casada; outros $12 \%$ divorciados e $6,8 \%$ viviam em uniáo consensual, enquanto $28,6 \%$ eram solteiros (12).

Os dados encontrados por Ximenes Neto e cols. [10]; ABEN [11] e Marsiglia [12] se assemelham com os desta pesquisa, que aponta o seguinte perfil: Auxiliares de enfermagem: 13 (59\%) estavam na faixa etária acima de 38 anos; 20 (91\%) eram do sexo feminino; 10 (45\%) eram casados; 13 (59\%) possuíam o ensino médio completo; 17 (72\%) tinham renda mensal de mais de um salário mínimo. Técnicos de enfermagem: dois (67\%) estavam na faixa etária acima de 38 anos; três (100\%) eram do sexo feminino; dois (67\%) eram casados; três (100\%) possuíam o ensino médio completo; dois (67\%) tinham renda mensal de mais de um salário mínimo.

\section{Açóes desenvolvidas pelos auxiliares e técnicos de enfermagem na sala de vacina}

As ações dos auxiliares e técnicos de enfermagem estão analisadas em uma mesma tabela, pois não há distinção de atividades entre os mesmos durante o trabalho nas salas de vacina.

Para um melhor detalhamento e compreensão das açôes desenvolvidas pelo auxiliar e o técnico de enfermagem expostas nas Tabelas II a VI, optou-se por descrever, as funçóes da equipe que atua na sala de vacina, que são: manter a ordem e limpeza da sala, conforme orientaçóes técnicas; prover, periodicamente, as necessidades de material e imunobiológicos; manter as condiçóes ideais de conservação dos imunobiológicos; manter os equipamentos em boas condições de funcionamento; encaminhar e dar destino adequado aos imunobiológicos inutilizados e ao lixo da sala de vacinação; orientar e prestar assistência à clientela, com segurança, responsabilidade e respeito; registrar a assistência prestada nos impressos adequados; manter o arquivo em ordem; e avaliar, sistematicamente, as atividades desenvolvidas [13]. 
Tabela II - Acolhimento, orientações e registro de informações desenvolvidas pelos auxiliares e técnicos de enfermagem da ESF, na sala de vacina. Sobral/CE, fev 2008.

\begin{tabular}{cccccccc}
\hline Atividade & D & S & Q & M & R & NR & N \\
\hline $\begin{array}{l}\text { Acolhe a clientela } \\
\text { na sala de vacina }\end{array}$ & 21 & 3 & - & 1 & - & - & - \\
\hline Registra as vacinas & & & & & & &
\end{tabular}

$\begin{aligned} & \text { Registra as vacinas } \\ & \text { a serem adminis- } \\ & \text { tradas no cartão }\end{aligned}$
$\begin{aligned} & \text { da criança } \\ & \text { da }\end{aligned}$

Realiza registro das vacinas

$\begin{array}{llllllll}\text { administradas no } & 11 & 3 & 1 & 1 & 2 & 5 & 2\end{array}$

cartão controle - o

cartão espelho

Orientam a clien-

tela acerca dos

imunobiológicos

a serem adminis-

trados e possíveis

reações e efeitos

adversos

\begin{tabular}{lllllllll}
\hline $\begin{array}{l}\text { Orienta a clientela } \\
\text { acerca do retorno }\end{array}$ & & & & & & & & \\
para adminis- & & & & & & & & \\
tração de doses & 22 & 2 & - & 1 & - & - & - \\
subsequentes do & & & & & & & & \\
esquema vacinal & & & & & & & & \\
\hline
\end{tabular}

Registra os

imunobiológicos

administrados em

$212-2-\quad-\quad-$

mapa diário

Realiza preenchi-

mento do boletim

mensal de doses

aplicadas

Realiza preenchi-

mento do mapa

de inutilização de

$213-1--\quad-$

imunobiológicos

Verifica e anota $o$

prazo de validade

dos imunológi-

$144-3-13$

cos em impresso

próprio

Realiza preenchi-

mento da ficha de

investigação de

$21-\quad-1822$

efeitos adversos

D - Diariamente, S - Semanalmente, Q -Quinzenalmente,

$M$ - Mensalmente, $R$ - Raramente, NR - Não realiza/Nunca

realizou este procedimento, $\mathrm{N}$ - Não respondeu.
Ximenes Neto e Costa afirmam que a formação profissional em saúde, no Brasil, “ainda está voltada para a clínica hospitalar e para a cura, baseando-se nas especialidades e para atençáo a eventos agudos em sistema de saúde fragmentado. Daí, a descontextualização dos trabalhadores da saúde para atuação na ESF” [10].

Para Mendes, esse obstáculo apresenta-se crucial em duas dimensóes: a ideológica, porque o sistema de formação de profissionais da saúde funciona como aparelho ideológico reprodutor da ideologia flexneriana; e a cognitivo-tecnológica, porque os conhecimentos e as tecnologias produzidas ou difundidas não guardam coerência. Ele ainda aponta esses obstáculos como um forte impeditivo à institucionalizaçáo da ESF, especialmente no espaço educacional corporativo [14].

A Tabela II mostra que 21 (84\%) dos sujeitos relataram que realizam o acolhimento da clientela diariamente. $\mathrm{O}$ acolhimento, segundo a Política Nacional de Humanização (PNH), é “[...] uma ação tecnoassistencial que pressupóe a mudança da relaçáo profissional/usuário e sua rede social, através de parâmetros técnicos, éticos, humanitários e de solidariedade, reconhecendo o usuário como sujeito e participante ativo no processo de produçáo da saúde. [...] é um modo de operar os processos de trabalho em saúde de forma a atender a todos que procuram os serviços de saúde, ouvindo seus pedidos e assumindo, no serviço, uma postura capaz de acolher, escutar e pactuar respostas mais adequadas aos usuários. Implica prestar um atendimento com resolutividade e responsabilizaçáo, orientando, quando for o caso, o cliente e a família em relação a outros serviços de saúde para a continuidade da assistência e estabelecendo articulaçóes com esses serviços para garantir a eficácia desses encaminhamentos" [15].

Quanto ao registro no cartáo de vacina, 22 (88\%) dos sujeitos referiram que registram os imunobiológicos administrados. Em relação à anotação no cartáo espelho, cinco responderam que este registro é da competência da ACS e apenas $11(44 \%)$ entrevistados o fazem diariamente. O cartão controle é um impresso de utilização interna do CSF, para o controle dos sujeitos vacinados ou que tenham aprazamento. Apesar da existência do prontuário familiar, é imprescindível a existência do cartáo controle na sala de vacina [16].

Sobre a orientaçáo quanto à vacina, suas possíveis reaçóes e efeitos adversos, 21 (84\%) disseram repassar estas informaçóes no dia a dia e realizar 
preenchimento da ficha de investigaçáo de efeitos adversos, quando necessário.

Na perspectiva de uma boa organização da sala de vacina, os profissionais da saúde devem estar atentos, também, aos eventos adversos após a vacinação, a exemplo de manifestação de doenças, sintomas leves ou graves, podendo ser causadas pela vacina, pois nenhuma vacina é isenta de riscos [16]. Nesse caso é extremamente necessária a "avaliação clínica e laboratorial desses casos, para estabelecimento rigoroso do diagnóstico etiológico, com a finalidade de que o evento adverso, a sequela ou mesmo o óbito não sejam atribuídos à vacina, sem fundamentação científica” [17]. Para um maior controle, é necessária à vigilância epidemiológica dos eventos adversos pós-vacinação. A equipe da ESF deve preencher o formulário próprio e, em seguida, encaminhá-lo ao nível central. A vigilância epidemiológica permite "subsidiar a padronização de condutas, tanto em relação a esses eventos, quanto em termos de normas e procedimentos de vacinação" [18].

Tabela III - Ações desenvolvidas na organização do refrigerador e caixas térmicas de imunobiológicos.

Sobral - Ceará, fev. 2008.

\begin{tabular}{|c|c|c|c|c|c|c|c|}
\hline Atividade & $\mathrm{D}$ & $S$ & $Q$ & $M$ & $\mathrm{R}$ & NR & $\mathrm{N}$ \\
\hline $\begin{array}{l}\text { Organiza refrigera- } \\
\text { dor de imunobioló- } \\
\text { gicos conforme as } \\
\text { normas do Ministé- } \\
\text { rio da Saúde }\end{array}$ & 9 & 8 & 4 & 1 & 2 & - & 1 \\
\hline
\end{tabular}

Acondiciona o gelo

reciclável no refri-

gerador lateral e

paralelamente um

$1932-\quad-\quad-1$

após o outro no

congelador

Organiza a $1^{a}$ pra-

teleira do refrigera-

dor, acondicionando

as vacinas virais que

$\begin{array}{lllllll}14 & 4 & 1 & 5 & - & - & 1\end{array}$

podem ser conge-

ladas

Organiza a $2^{a}$ pra-

teleira do refrigera-

dor, acondicionando

as vacinas virais

$\begin{array}{lllllll}14 & 4 & 1 & 5 & - & - & 1\end{array}$

que não podem ser

congeladas, as bac-

terianas e os soros
Organiza a $3^{a}$ prate-

leira do refrigerador,

acondicionando os

$\begin{array}{lllllll}14 & 4 & 1 & 5 & - & - & 1\end{array}$

diluentes

Verifica a temperatu-

ra diária do refrige-

rador de imunobio-

lógicos e registra no

$211-\quad-2-1$

mapa de controle de

temperatura

Realiza limpeza

do refrigerador de

imunobiológicos,

quando necessário

Organiza imunobio-

lógicos nas caixas

térmicas com gelo

reciclável (baterias)

e depósito para

$213-\quad-\quad-1$

imunobiológicos

evitando choque

térmico

Organiza imunobio-

lógicos nas caixas

térmicas separando

os virais dos bacte-

rianos

Acopla seringa com

agulha aos frascos

de imunobiológicos

injetáveis, que estão

$153-\quad-3 \quad 3 \quad 1$

dispostos na caixa

térmica

\begin{tabular}{lllllllll}
\hline $\begin{array}{l}\text { Verifica temperatura } \\
\text { das caixas térmicas }\end{array}$ & 3 & 2 & - & - & 7 & 11 & 2
\end{tabular}

Ao final do expe-

diente lava as caixas

térmicas com água

$154-\quad-312$

e sabão

D - Diariamente, S - Semanalmente, Q - Quinzenalmente, $M$ - Mensalmente, $R$ - Raramente, NR

- Não realiza/Nunca realizou este procedimento,

$\mathrm{N}$ - Não respondeu.

De acordo com a Tabela III, nove (36\%) dos auxiliares e técnicos de enfermagem organizavam os refrigeradores, diariamente, segundo as normas do MS, desenvolvendo as seguintes açóes: 19 (76\%) acondicionavam o gelo reciclável no refrigerador adequadamente; 14 (56\%) organizavam as vacinas nas prateleiras conforme recomendado; 11 (44\%) reali- 
zavam limpeza do refrigerador a cada quinze dias; 21 (84\%) verificavam a temperatura diária do refrigerador e registravam no mapa de controle de temperatura.

O mapa de controle diário da temperatura do refrigerador é utilizado para o acompanhamento e a análise dos registros, com o intento de verificar as temperaturas a que estão submetidos os imunobiológicos, detectando falhas na rede de frio [13]. Devendo a mesma ser verificada, pelo menos, duas vezes ao dia, inicialmente, na abertura pela manhã, e ao final do expediente, quando os imunobiológicos forem acondicionados de volta no refrigerador. A verificação e registro da temperatura diariamente, no mínimo duas vezes, é um excelente indicador de qualidade relativo ao armazenamento dos imunobiológicos.

Ximenes Neto com base nas normas do MS recomenda que a limpeza do refrigerador deva ocorrer a cada 15 dias ou quando a camada de gelo atingir $0,5 \mathrm{~cm}$. Durante a limpeza, transferir todos os imunobiológicos para caixa térmica com gelo reciclável e termômetro de cabo extensor, a uma temperatura de $+2^{\circ} \mathrm{C} \mathrm{a}+8^{\circ} \mathrm{C}$. Náo alterar o termostato durante a limpeza da geladeira. A limpeza deve ser realizada, utilizando-se um pano umedecido em água e sabáo neutro, e enxugá-lo com pano limpo e seco. Jamais deverá ser despejada água no interior do refrigerador. Após a limpeza, ligar o refrigerador e recolocar o gelo, o termômetro, as garrafas. Fechar as portas e por volta de uma hora, quando a temperatura estiver entre de $+2^{\circ} \mathrm{C} \mathrm{a}+8^{\circ} \mathrm{C}$, recolocar as vacinas e soros [16].

A organização do refrigerador de imunobiológicos, conforme as normas técnicas do MS, sempre foi motivo de grandes controvérsias dos profissionais no dia a dia do serviço, devido principalmente, a pouca ou nenhuma qualificação. Tal situação fez com que, historicamente, a organização da sala de vacina agregasse muitos mitos, talvez até subjetividades.

Quanto à organização das caixas térmicas para acondicionamento dos imunobiológicos, 21 $(84 \%)$ ordenavam as baterias nas mesmas todos os dias; $20(80 \%)$ organizavam as vacinas em caixas térmicas separadas, uma para virais e outra para bacterianas; três (12\%) dos sujeitos responderam que não acoplam a seringa com agulha aos frascos, fato que pode comprometer a qualidade dos imunobiológicos, devido aos riscos de contaminação. Profissionais de 11 (44\%) dos CSF revelaram não verificar a temperatura na caixa de vacina por não possuírem termômetro na unidade.
A caixa térmica de uso diário deve ser organizada utilizando gelo reciclável ao fundo, nas laterais/ paredes e, em seguida, colocar os imunobiológicos ao centro, dentro de copo descartável perfurado, para evitar o contato direto com o gelo, e mantendo sempre uma seringa adaptada para evitar contaminação por meio do canhão da agulha [19].

Tabela IV - Métodos e técnicas de administração e organização de imunobiológicos e insumos do refrigerador e caixas térmicas de imunobiológicos. Sobral/CE, fev 2008.

\begin{tabular}{|c|c|c|c|c|c|c|c|}
\hline Atividade & D & $\mathrm{S}$ & $Q$ & $M$ & $R$ & NR & $\mathrm{N}$ \\
\hline $\begin{array}{l}\text { Realiza diluição de } \\
\text { imunobiológicos } \\
\text { para administração } \\
\text { por via IM, SC ou ID }\end{array}$ & 20 & 4 & - & 1 & - & - & - \\
\hline $\begin{array}{l}\text { Administra imuno- } \\
\text { biológicos por via } \\
\text { oral na clientela }\end{array}$ & 22 & 2 & - & - & - & - & 1 \\
\hline $\begin{array}{l}\text { Administra imuno- } \\
\text { biológicos por via } \\
\text { parenteral - IM, SC } \\
\text { e ID - na clientela }\end{array}$ & 21 & & & 2 & & & 2 \\
\hline
\end{tabular}

Realiza lavagem das mãos antes da administração de imunobiológicos de cada cliente

Após abertura do frasco de imunobiológicos, registrando no mesmo, data e horário para conferência de prazo de validade.

\begin{tabular}{|c|c|c|c|c|c|c|c|}
\hline $\begin{array}{l}\text { Despreza imunobio- } \\
\text { lógicos com prazo de } \\
\text { validade expirado, } \\
\text { temperatura alterada } \\
\text { ou que tenham sido } \\
\text { contaminados em re- } \\
\text { cipiente apropriado. }\end{array}$ & 10 & 6 & - & - & 7 & 1 & 1 \\
\hline $\begin{array}{l}\text { Realiza esterilização } \\
\text { em autoclave dos } \\
\text { frascos de imunobio- } \\
\text { lógicos de vírus vivo } \\
\text { atenuado e BCG. }\end{array}$ & 2 & 5 & 4 & 1 & 5 & 7 & 1 \\
\hline $\begin{array}{l}\text { Organiza e classi- } \\
\text { fica as seringas em } \\
\text { depósito específico. }\end{array}$ & 13 & 8 & & 3 & & 1 & - \\
\hline
\end{tabular}


D - Diariamente, $S$ - Semanalmente, $Q$-Quinzenalmente, $M$ - Mensalmente, $R$ - Raramente, Não realiza/Nunca realizou este procedimento, $\mathrm{N}$ Não respondeu.

IM - intramuscular, SC - subcutânea e ID - intra-dérmica.

Quanto à diluição dos imunobiológicos, 20 $(80 \%)$ relataram realizar este procedimento diariamente. Em um CSF localizado na zona rural, que não possui espaço exclusivo para sala de vacina, realiza administração de imunobiológicos somente uma vez por semana. Esta situação nos remete ao seguinte questionamento: Nos casos de sujeitos em uso de esquema completo da vacina antirrábica, o que fazem? São desenvolvidas outras estratégias para assistir esta demanda?

Dos auxiliares e técnicos do estudo, 23 (92\%) asseguraram fazer higienização das mãos antes de cada procedimento. A lavagem das mãos ou higienizaçáo das mãos, segundo a Agência Nacional de Vigilância Sanitária-ANVISA é a "[...] medida individual mais simples e menos dispendiosa para prevenir a propagação das infecçóes relacionadas à assistência à saúde [...]”. A Organização Mundial da Saúde (OMS), com o objetivo de garantir a segurança no cuidado à clientela nos serviços de saúde, lançou em 2004, a "Aliança Mundial para Segurança do Paciente", firmando pacto com vários países. A aliança tem como prioridade o tema higienização das mãos. "[...] Embora a higienizaçáo das máos seja a medida mais importante e reconhecida há muitos anos na prevençáo e controle das infecçóes nos serviços de saúde, colocá-la em prática consiste em uma tarefa complexa e difícil" [20].

Dos sujeitos do estudo, 16 (56\%) registravam e anotavam no frasco de imunobiológico, data e horário de abertura do mesmo, dois (8\%) admitiram não fazê-lo. Os registros asseguram a qualidade dos imunobiológicos, por meio de características de tempo de validade e uso.

Em relação ao desprezo dos imunobiológicos com prazo de validade expirado, 10 (40\%) mantinham esta prática diariamente, um (4\%) nunca realizava e dois (8\%) encaminhavam para o Centro de Zoonoses para inutilização ou devolviam para Central de Imunização Municipal. No que concerne à esterilizaçáo em autoclave, um (4\%) fazia a cada três meses na própria unidade e quatro $(16 \%)$ encaminhava os frascos de vacina para o Centro de Zoonoses; 16 (56\%) organizavam e classificam em depósito específico diariamente, um (4\%) relatou que não tinha espaço na unidade. No Centro de Zoonoses está localizada a Coordenaçáo Municipal de Vigilância à Saúde e em seus espaços há equipamentos, a exemplo dos autoclaves, que realizam procedimentos como esterilização e incineração de material.

Quanto às sobras diárias, vacinas com prazo de validade expirado ou inutilizado, a principal ação para o tratamento de resíduos infectantes é a esterilização a vapor ou a incineração. Segundo recomendaçóes do MS, "os imunobiológicos compostos por microorganismos vivos atenuados - vacinas contra sarampo, a poliomielite, a caxumba, a rubéola, a febre amarela e a tuberculose - constituem material biológico infectante e, como tal, devem receber tratamento prévio antes de serem desprezados". No que se refere aos imunobiológicos compostos por "produtos de bactérias ou bactérias mortas, vírus inativados e engenharia genética - as vacinas contra o tétano, a tríplice e a dupla adulto e infantil, pneumococos, Haemophilus influenzae, hepatites, pólio injetável Salk e raiva não precisam receber tratamento especial para serem inutilizados”. O processo de inutilização dos imunobiológicos compostos por microorganismos vivos deve ser realizado em autoclave, preferencialmente, durante 15 minutos, a uma temperatura de $121 \mathrm{oC}$ a $127 \mathrm{oC}$, devendo os frascos estar abertos para o processamento. Após a autoclavagem, os frascos podem ser desprezados como lixo comum [21].

O não-processamento dos frascos de imunobiológicos com prazo de validade expirado, temperatura alterada ou que tenham sido contaminados ou vazios de vírus vivo atenuado e BCG, pode vir a permitir a contaminação do solo, a ativação dos vírus, dentre outros; dependendo da forma de manejo. A partir daí, o serviço de saúde que deveria ser protetor e fomentador da qualidade de vida, com tal prática passa a ser um risco para o território, determinantes ecológicos e a manutenção da salubridade das famílias e sujeitos.

Tabela V - Ações de limpeza e destino dos resíduos sólidos da sala de vacina. Sobral/CE, fev 2008.

\begin{tabular}{lllllll}
\hline ATIVIDADE & D & S & Q & M & $R$ & $N$ \\
\hline $\begin{array}{l}\text { Orienta a limpeza da sala } \\
\text { de vacina }\end{array}$ & 14 & 4 & 1 & 2 & 2 & 2 \\
\hline $\begin{array}{l}\text { Realiza a limpeza da banca- } \\
\text { da e da pia com água e sa- }\end{array}$ & 21 & 2 & - & - & 1 & 1 \\
bão, em que estão dispostas & & & & & & \\
as caixas térmicas ao final \\
do expediente
\end{tabular}




Despreza o lixo da sala de $20 \quad 4 \quad-\quad-\quad-\quad 1$
vacina, separando os resíduos
perfurantes (agulhas, ampolas
de vacinas ou frascos de vidro
que se quebram facilmen-
te), dos resíduos infectantes
(algodão, papel absorvente e
as seringas descartáveis), em
recipientes distintos
D - Diariamente, S - Semanalmente, Q - Quinze-
nalmente, M - Mensalmente, R - Raramente, N -
Não respondeu.

A Tabela V mostra que 14 (56\%) dos auxiliares e técnicos de enfermagem orientavam a limpeza da sala de vacina diariamente; 21 (84\%) limpavam a bancada e a pia onde estão dispostas as caixas térmicas no final do expediente. A rotina de limpeza da sala de vacina deve manter a periodicidade diária, antes e depois do expediente, ou quando necessário, utilizando-se solução desinfetante. Semanalmente, o chão deve ser limpo com água e sabão, passando, em seguida, soluçáo desinfetante. Já a cada 15 dias, o teto, as paredes, as janelas, luminárias e portas, também devem ser limpos com solução desinfetante [22].

Dos sujeitos, $20(80 \%)$ relataram desprezar o lixo da sala de vacina todos os dias separando os resíduos infectantes dos perfurantes. O lixo da sala de vacina é classificado como perigoso e comum. $\mathrm{O}$ lixo perigoso é classificado em três categorias: material biológico - são os imunobiológicos, referentes às sobras diárias, que passaram do prazo de validade ou que sofreram alteração de temperatura; resíduos perfurantes - agulhas, ampolas de vacinas ou frascos de vidro que se quebram facilmente; e outros resíduos infectantes - algodáo, papel absorvente e as seringas descartáveis. O lixo comum são os demais resíduos da sala de vacina [13].

Durante a produção do lixo, seja perigoso ou comum, o profissional que atua na sala de vacina deve ter a responsabilidade de separá-lo, para facilitar o tratamento do lixo perigoso e reduzir os riscos de contaminaçáo dos sujeitos que o manuseiam [16].

Tabela VI - Demais ações realizadas pelos auxiliares e técnicos de enfermagem no território da ESF. Sobral/ CE, fev 2008.

\begin{tabular}{llllllll}
\hline \multicolumn{1}{c}{ ATIVIDADE } & D & S & Q & M & R & NR & N \\
\hline $\begin{array}{l}\text { Realiza visitas aos } \\
\text { lares para busca de }\end{array}$ & 1 & 3 & 1 & 2 & 10 & 7 & 1 \\
faltosos & & & & & & & \\
\hline
\end{tabular}

\begin{tabular}{|c|c|c|c|c|c|c|}
\hline $\begin{array}{l}\text { Solicita material de } \\
\text { expediente e insumos }\end{array}$ & -5 & 2 & 15 & 2 & - & 1 \\
\hline $\begin{array}{l}\text { Participa de ativida- } \\
\text { des educativas sobre } \\
\text { a importância da } \\
\text { vacinação }\end{array}$ & - & - & 2 & 22 & - & 1 \\
\hline $\begin{array}{l}\text { Avalia com a equi- } \\
\text { pe as coberturas } \\
\text { vacinais da área de } \\
\text { abrangência da uni- } \\
\text { dade de saúde }\end{array}$ & -2 & - & 11 & 4 & 7 & 1 \\
\hline $\begin{array}{l}\text { Participa de campa- } \\
\text { nhas de multivacina- } \\
\text { ção }\end{array}$ & $\begin{array}{ll}- & 1\end{array}$ & - & 3 & 21 & - & - \\
\hline $\begin{array}{l}\text { Realiza campanhas } \\
\text { de vacina em esco- } \\
\text { las, indústrias dentre } \\
\text { outros }\end{array}$ & -2 & - & 2 & 21 & - & - \\
\hline $\begin{array}{l}\text { D - Diariamente, S - Se } \\
\text { nalmente, } M \text { - Mensaln } \\
\text { - Não realiza/ Nunca r } \\
N \text { - Não respondeu. }\end{array}$ & $\begin{array}{l}\text { anal } \\
\text { ente, } \\
\text { alizou }\end{array}$ & & 8 & $-Q u$ & $\begin{array}{l}\text { nze- } \\
\text { NR } \\
\text { ento, }\end{array}$ & \\
\hline
\end{tabular}

Quanto à visita ao lar, em busca de faltosos, sete $(28 \%)$ relataram solicitar às ACS que os procurassem quinzenalmente; 22 (88\%) participavam raramente de atividades educativas; 11 (44\%) avaliavam com a equipe da ESF a cobertura vacinal mensalmente, sendo que em quatro (16\%) CSF quem analisava era a gerente e em três (12\%) eram as ACS; $84 \%$ participavam de campanha de multivacinação regularmente em escola, indústrias dentre outros.

Quanto à organização de equipes móveis para alcançar a cobertura vacinal nos territórios da ESF, o MS sugere o seguinte: "vacinadores preparados para administrar todas as vacinas do esquema básico; quantidade de vacinas e insumos suficiente para atender à estimativa de crianças, gestantes e outros grupos de risco; tempo de permanência suficiente para vacinar toda população-alvo; escolha das datas e horários que levem em conta a maneira de viver da população, dias da semana mais adequados - dias de feira, de missa etc. - e épocas do ano - estação mais seca para evitar dificuldades de locomoção; cronograma de viagens que inclua o retorno à área para contemplar esquemas, considerando o intervalo entre as doses; transporte e conservação dos imunobiológicos feitos em condiçóes adequadas; disponibilidade de mapas ou croquis da área de atuação de cada equipe móvel; registro das vacinas administradas, segundo o tipo vacina, dose e 
idade, nos formulários de rotina; e preenchimento do comprovante de vacinação - cartáo da criança ou do adulto ou outro documento - para todas as pessoas vacinadas" [13].

\section{Conclusão}

O estudo mostra a não-distinção de ações desenvolvidas pelos auxiliares e técnicos de enfermagem na sala de vacina, o MS e as Secretarias Estaduais e Municipais da Saúde devem se posicionar quanto à definição das práticas e perfis profissionais, e a própria criação do cargo de técnico como emprego público

É importante ressaltar que, apesar de auxiliares e técnicos de enfermagem estarem assumindo e executando inúmeras açôes na sala de vacina, a responsabilidade técnica pela mesma é do enfermeiro, cabendo a este gerenciá-la, supervisionar o processo de trabalho da equipe de enfermagem, além de estar, constantemente, qualificando-os, com o intuito de melhorar a qualidade do trabalho e reduzir as deficiências identificadas neste estudo.

No entanto, percebe-se que os auxiliares e técnicos de enfermagem devem buscar realizar, com mais frequência, açóes de educação, promoção da saúde e prevenção de doenças; além de apropriar-se de medidas de segurança individual e coletiva e do cuidado com a conservação dos imunobiológicos. Quanto a esta situação, sugere-se que seja desenvolvido processo de educaçáo permanente dos auxiliares e técnicos de enfermagem, em conjunto com os enfermeiros, sobre imunização e sala de vacina.

\section{Referências}

1. Brasil. Ministério da Saúde. Departamento de Atenção Básica. Guia Prático do Programa de Saúde da Família. Brasília: Ministério da Saúde; 2001.

2. Sousa MF. A coragem do PSF. São Paulo: HUCITEC; 2001.

3. Peduzzi M. Equipe multiprofissional de saúde: a interface entre trabalho e interação [Tese]. Campinas: Faculdade de Ciências Médicas, Universidade Estadual de Campinas; 1998.

4. Brasil. Ministério da Saúde. Secretaria de Atenção à Saúde. Departamento de Atenção Básica. Política Nacional de Atenção Básica. Brasília: Ministério da Saúde; 2006.

5. Brasil. Conselho Federal de Enfermagem-COFEN. Associação Brasileira de Enfermagem-ABEN. O exercício da Enfermagem nas instituições de saúde no Brasil - 1982/1983: força de trabalho em enfermagem. Rio de Janeiro: COFEN/ABEN; 1985.
6. Girardi SN, Carvalho CL. Mercado de trabalho e regulaçáo das profissóes de saúde. In: Negri B, Faria $\mathrm{R}$, Vianna AL, organizadores. Recursos humanos em saúde: política, desenvolvimento e mercado de trabalho. Campinas: Instituto de Economia/Unicamp; 2002.

7. Brasil. Ministério da Saúde. Secretaria de Gestão de Investimentos em Saúde. Projeto de Profissionalização dos Trabalhadores da Área de Enfermagem-PROFA̧E. Sinais de mercado de trabalho do pessoal de enfermagem no Brasil. Formação 2001;1(1):47-72.

8. Organización Mundial de la Salud-OMS. La Enfermería más allá del año 2000: Informe de un grupo de estudio de la OMS. Serie de informes técnicos; 842 . Ginebra: OMS; 1994.

9. Ferretti C J. Formação profissional e reforma do ensino técnico no Brasil: anos 90. Educação e Sociedade, 1999;18(59):225-69.

10. Ximenes Neto FRG, Costa MCF, Rocha J, Cunha ICKO. Auxiliares e técnicos de enfermagem na Saúde da Família: perfil sociodemográfico e necessidades de qualificação. Trabalho, educação e saúde (Online), 2008;6:51-64.

11. Associação Brasileira de Enfermagem-ABEn, organizador. Perfil de açóes do técnico de enfermagem no Brasil. Brasília: Ministério da Saúde; 2003.

12. Marsiglia RMG. Auxiliares de enfermagem: mercado de trabalho, perfil, satisfaçáo e expectativas no Programa de Saúde da Família na cidade de São Paulo, Trabalho, Educação e Saúde 2006;4(1):109-30.

13. Brasil. Ministério da Saúde. Fundação Nacional de Saúde-FUNASA. Manual de procedimentos para vacinação. Brasília: Ministério da Saúde/FUNASA, 2001.

14. Mendes EV. A atenção primária à saúde no SUS. Fortaleza: Escola de Saúde Pública do Ceará; 2002. 92 p.

15. Brasil. Ministério da Saúde. Secretaria-Executiva. Núcleo Técnico da Política Nacional de Humanização. HumanizaSUS: acolhimento com avaliação e classificação de risco: um paradigma ético-estético no fazer em saúde. Brasília: Ministério da Saúde; 2004.

16. Ximenes Neto FRG. Organização do Centro de Saúde da Família. Sobral: Escola de Formaçáo em Saúde da Família Visconde de Sabóia-EFSFVS; 2007. 83p. (mimeo).

17. Brasil. Ministério da Saúde. Fundação Nacional de Saúde-FUNASA. Manual de normas de vacinação. Brasília: Ministério da Saúde/FUNASA; 2001.

18. Brasil. Ministério da Saúde. Programa - vacinação e doenças imunopreviníveis. Brasília: Ministério da Saúde; 2001.

19. Ceará. Secretaria da Saúde de Estado-SESA. Coordenadoria de Políticas em Saúde. Núcleo de Normatização da Atençáo à Saúde da Criança. Informe técnico. Fortaleza: SESA; 2006.

20. Brasil. Ministério da Saúde. Agência Nacional de Vigilância Sanitária-ANVISA. higienização das mãos em serviços de saúde. Brasília-DF: ANVISA; 2007.

21. Brasil. Ministério da Saúde. Fundação Nacional de Saúde-FUNASA. Capacitaçáo de pessoal em sala de vacinação: manual do monitor. Brasília: Ministério da Saúde/FUNASA; 2001.

22. Brasil. Ministério da Saúde. Fundação Nacional de Saúde-FUNASA. Capacitaçáo de pessoal em sala de vacinação: manual do treinando. Brasília: Ministério da Saúde/FUNASA; 1999. 